Gut, 1979, 20, 775-779

\title{
Cell proliferation of pericryptal fibroblasts in the rat colon mucosa
}

\author{
A. P. MASKENS, ${ }^{1}$ J. R. RAHIER, F. P. MEERSSEMAN, \\ ROSE-MARIE DUJARDIN-LOITS, AND J. G. HAOT \\ From the Service d'Anatomie Pathologique, Université Catholique de Louvain, Cliniques St Luc, \\ 1200 Brussels, Belgium
}

SUMMARY The turnover of pericryptal fibroblasts in the rat colon mucosa was analysed after in vivo incorporation of tritiated thymidine. Thirty-six rats were serially killed one hour to 21 days after intraperitoneal injection of the radionuclide. At one hour, the labelling index of pericryptal fibroblasts was only $2.44 \%$; labelled fibroblasts were slightly predominant along the lower two-thirds of the crypts. Within 24 hours, most underwent at least one cell division. No migration was observed and a significant proportion of labelled fibroblasts was still present after three weeks. It is concluded that those fibroblasts constitute a slowly renewing cell population. The data failed to confirm the hypothesis of an 'en bloc' migration of fibroblasts in synchrony with the epithelial cells.

The intestinal epithelium is a tissue in which cell proliferation, differentiation, and migration occur throughout life. In the small intestine, proliferating cells are restricted to the crypts; the turnover time of the epithelial cell population is approximately 48 to 72 hours (Quastler and Sherman, 1959; Messier and Leblond, 1960; Cairnie et al., 1965). In the colon, proliferating cells are restricted to the lower twothirds of the crypts and the turnover ranges between 34 and 140 hours (as estimated from data by Messier, 1960; Lipkin and Quastler, 1962; Sawicki et al., 1968; Sawicki and Rowiński, 1970; Chang and Nadler, 1975). The mechanisms which control this continuous process are still poorly understood.

The clear description by Kaye et al. (1968) of a colonic mesenchymal pericryptal sheath tightly surrounding the glandular epithelium suggested possible epitheliomesenchymal interactions, a finding which may be borne out by analogous studies of developmental conditions in the duodenum (Mathan et al., 1972). Bearing the results of tritiated thymidine $\left({ }^{3} \mathrm{H}-\mathrm{TdR}\right)$ incorporation studies in mind, Pascal et al. (1968) also proposed the hypothesis of an 'en bloc' synchronous migration of the whole epitheliomesenchymal complex, including the epithelial cells and pericryptal fibroblasts. The aim of the present

\footnotetext{
${ }^{1}$ Address for reprint requests: Dr. Alain P. Maskens, Clinique Saint-Michel, Cancer Research Unit, B-1040 Brussels, Belgium.
}

Received for publication 9 March 1979 study was to document further the turnover of pericryptal fibroblasts implied by the above hypothesis, using ${ }^{3} \mathrm{H}-\mathrm{TdR}$ labelling techniques.

\section{Methods}

Thirty-six male BD IX rats, about 24 weeks of age and fed a standard diet and tap water ad libitum, were used in this experiment. They were killed in groups of six, at one, 12, and 24 hours, three, seven and 21 days after receiving intraperitoneally 0.5 $\mu \mathrm{Ci} / \mathrm{g}$ tritiated thymidine $\left({ }^{3} \mathrm{H}-\mathrm{TdR}\right)$ (Amersham, England), specific activity $2 \mathrm{Ci} / \mathrm{mM}$. Samples of the mucosa from the distal descending colon were embedded in Epon. One $\mu \mathrm{m}$ thick sections were coated with NTB-emulsion (Kodak, Rochester), developed after six or 10 weeks' exposure, and stained with nuclear fast red. All crypts of Lieberkühn that were adequately exposed from base to lumen in the sections were scored for the presence of ${ }^{3} \mathrm{H}$-TdR labelled pericryptal fibroblasts, of which the grain count (three or more grains) as well as position along the crypt were recorded. The latter was determined with reference to the position of the closest epithelial cell. In addition, 50 glands from each of six animals randomly chosen from the experimental group were scored for the number and position of all pericryptal fibroblasts, both labelled and unlabelled. Recognition of pericryptal fibroblasts was based on previously described histological criteria (Kaye et al., 1968). 
Results

The colonic mucosa is composed of a regular succession of cylindrical crypts perpendicular to the intestinal lumen. The monolayer of glandular epithelial cells is tightly surrounded by a so-called 'pericryptal sheath', consisting of the epithelial basement lamina, collagen fibres, and fibroblasts. The latter appear as fusiform cells closely lining the crypt surface. On $1 \mu \mathrm{m}$ thick midsagittal sections, an average of $7 \cdot 1$ pericryptal fibroblasts per gland were found, distributed along the entire length of the glands, with, however, a slight preponderance in the lower two-thirds (lower third, $36.3 \%$; middle third, $38.1 \%$; upper third, $25.6 \%$ ). There was little variation from one animal to the other (Table 1).

Data on ${ }^{3} \mathrm{H}-\mathrm{TdR}$ incorporation in the pericryptal fibroblasts at various intervals after a pulse injection of the radionuclide are detailed in Table 2. An average of almost 400 crypts per animal were analysed. In animals killed 60 minutes after the injection, the incidence of labelled fibroblasts was quite low, approximately one for every six glands of Lieberkühn or one for every 42 unlabelled fibroblasts (labelling index $2.44 \%$ ). Labelled fibroblasts were distributed all along the crypts (Fig. 1), with

Table 1 Number and distribution of pericryptal fibroblasts in rat colon mucosa

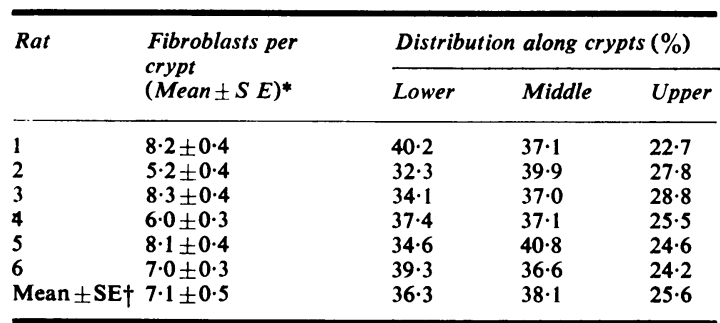

* Mean of 50 crypts per animal.

†Mean of six animals.

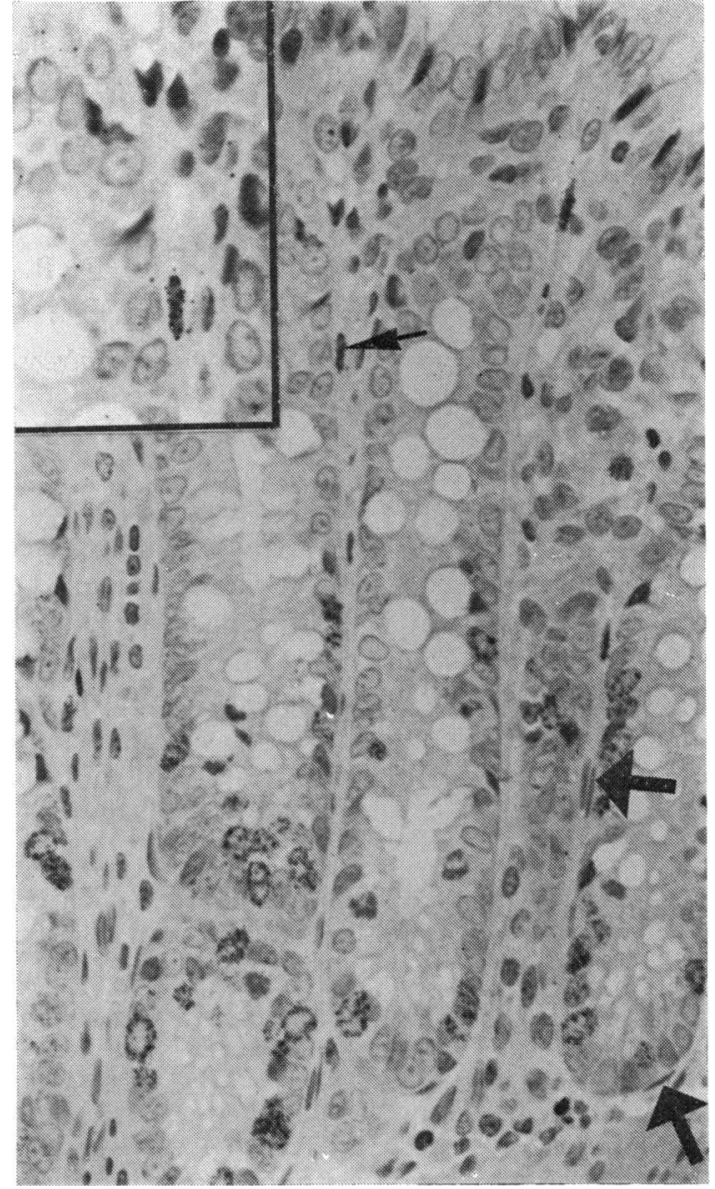

Fig. 1 Radioautograph of a $1 \mu$ section of crypts of Lieberkühn from a $B D I X$ rat killed one hour after an intraperitoneal injection of ${ }^{3} \mathrm{H}-\mathrm{TdR}$. Thick arrows indicate examples of pericryptal fibroblasts. The thin arrow shows a labelled fibroblast lining the upper third of a crypt (see insert). Nuclei of epithelial cells are labelled in the lower two-thirds of crypts only. Nuclear fast red, $\mathrm{NTB}_{2}$ emulsion, exposure six weeks, $x 375$.

Table 2 Number and distribution of labelled colon pericryptal fibroblasts at various intervals after an IP injection of tritiated thymidine

\begin{tabular}{|c|c|c|c|c|c|c|}
\hline \multirow[t]{2}{*}{ Interval } & \multirow{2}{*}{$\begin{array}{l}\text { Total crypts } \\
\text { analysed }\end{array}$} & \multirow{2}{*}{$\begin{array}{l}\text { Total no. } \\
\text { labelled } \\
\text { fibroblasts }\end{array}$} & \multirow{2}{*}{$\begin{array}{l}\text { Mean* no. } \\
\text { labelled fibroblasts } \\
\text { per crypt section }\end{array}$} & \multicolumn{3}{|c|}{ Crypt distribution (\%) of labelled fibroblasts* } \\
\hline & & & & Lower & Middle & Upper \\
\hline \multicolumn{7}{|l|}{ Hours } \\
\hline & 2385 & 367 & $0.17 \pm 0.04$ & $35 \cdot 6 \pm 1 \cdot 8$ & $39 \cdot 8 \pm 2 \cdot 5$ & $24 \cdot 7+3 \cdot 9$ \\
\hline 12 & 2221 & 331 & $0.16 \pm 0.02$ & $40 \cdot 4 \pm 5 \cdot 2$ & $39 \cdot 2 \pm 1 \cdot 2$ & $20 \cdot 4 \pm 5 \cdot 3$ \\
\hline 24 & 2542 & 640 & $0.26+0.03$ & $33 \cdot 7+3 \cdot 0$ & $43 \cdot 7 \pm 2 \cdot 8$ & $22 \cdot 6 \pm 2 \cdot 6$ \\
\hline \multicolumn{7}{|l|}{ Days } \\
\hline 7 & 3184 & 385 & $0.13 \pm 0.02$ & $36 \cdot 1 \pm 2 \cdot 1$ & $41 \cdot 4 \pm 3 \cdot 1$ & $22 \cdot 5 \pm 2 \cdot 2$ \\
\hline 21 & 5363 & 216 & $0.04 \pm 0.01$ & $32 \cdot 3 \pm 2 \cdot 1$ & $35 \cdot 3 \pm 2 \cdot 4$ & $32 \cdot 4 \pm 4 \cdot 1$ \\
\hline
\end{tabular}

* Mean of six rats $\pm S E$. 
again a slight preponderance in the two lower thirds comparable with that observed for the unlabelled fibroblasts as well, thus giving quite similar labelling indices at the various levels of the crypts (lower third, $2.41 \%$; middle third, $2.56 \%$, upper third, $2.30 \%$ ). Within 24 hours, the number of labelled fibroblasts rose by $53 \%$; it then slowly decreased, with significant values still present as late as three weeks after injection of the thymidine. The distribution of the labelled fibroblasts along the glands remained remarkably stable between the first hour and the seventh day after ${ }^{3} \mathrm{H}-\mathrm{TdR}\left(\varkappa^{2}\right.$ analysis: $0 \cdot 25>\mathrm{P}>0 \cdot 10$ ). The 21 st day distribution, however, indicated a relative increase in upper-third labelling.

Grain count studies are detailed in Figs. 2 and 3. An average of 2300 glands and 287 labelled fibroblasts was available for analysis in each group. To make groups comparable, they were normalised to 1000 glands each. In order to facilitate grain count and cell identification, radioautographs exposed during six weeks only were used for specimens from animals killed one to 24 hours after the ${ }^{3} \mathrm{H}-\mathrm{TdR}$ injection (Fig. 2), while a 10 week exposure was needed for the ones with a longer delay (Fig. 3); the 24 hour specimens, however, were analysed with both exposures, to serve as a reference in both groups.

Between the first and the 24th hour after ${ }^{3} \mathrm{H}-\mathrm{TdR}$, together with the increase in the number of labelled fibroblasts, there was an accumulation of nuclei with a reduced grain count (median grain count: one hour, 13; 24 hours, nine). After the first day, while the number of labelled fibroblasts decreased quite slowly, several retained high grain counts for as long as three weeks.

\section{Discussion}

Studies of the turnover of pericryptal fibroblasts in the gut mucosa are difficult for three reasons. As outlined by Marsh and Trier (1974), pericryptal fibroblasts can sometimes be difficult to identify, with possible confusion with capillary endothelial cells. In addition, labelled fibroblasts are infrequent findings (one for every six crypts scored), and large amounts of material have to be analysed to obtain significant results. Consequently also, labelled mitoses techniques are inapplicable. In this study, therefore, attempts were made to gather as accurate information as possible by using high resolution light microscopy techniques, by scoring large numbers of labelled fibroblasts, and by recording grain counts.

The ${ }^{3} \mathrm{H}-\mathrm{TdR}$ labelling data presented here confirmed the observation by Pascal et al. (1968) that colonic pericryptal fibroblasts constitute a renewing cell population. After a pulse injection of the radionuclide, a small fraction $(2.44 \%)$ of those cells became labelled. Most underwent at least one division within the 24 hours that followed the injection, as evidenced by increased labelling index and dilution of the grain density. In the subsequent days,
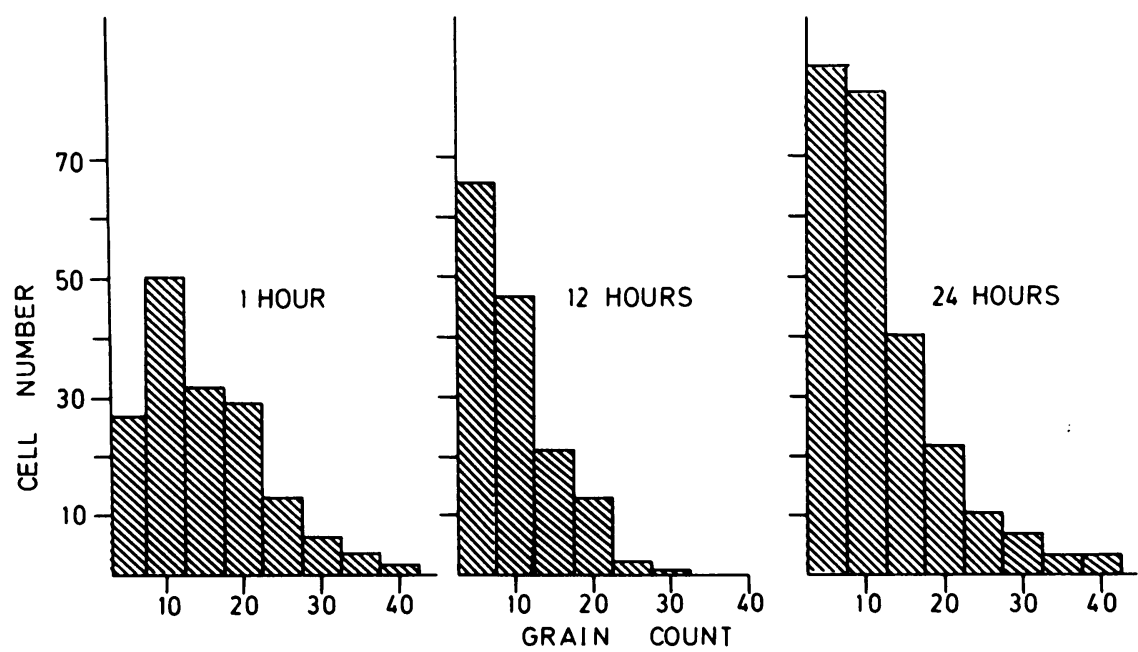

Fig. 2 Grain count study of pericryptal fibroblasts from the colon mucosa of rats killed one hour, 12, and 24 hours after an intraperitoneal injection of ${ }^{3} H-T d R$. Pooled data, average 2300 scored crypts from four to six animals per time interval. Exposure time of the radioautographs: six weeks. Ordinate: normalised frequency (fibroblasts per 1000 crypts). At 24 hours, the number of labelled fibroblasts is markedly increased, with accumulation of low grain counts. 


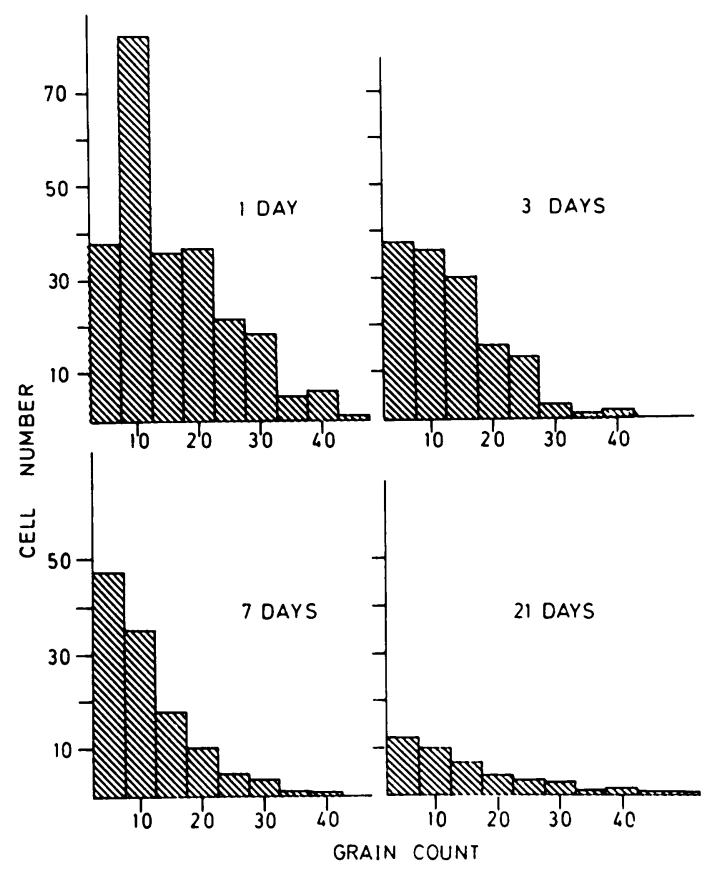

Fig. 3 Grain count study of pericryptal fibroblasts in the rat colon mucosa at one, three, seven, and 21 days after a pulse intraperitoneal injection of ${ }^{3} \mathrm{H}-\mathrm{TdR}$. Pooled data, average 2300 scored crypts from four to six rats per time interval. Exposure time of the radioautographs: 10 weeks. Ordinate, normalised frequency (fibroblasts per 1000 crypts). There is a slow decline of the label. At 21 days, the number of labelled fibroblasts still represents about one-fifth of the first day value, with, in several instances, high grain counts.

their number slowly decreased, an indication that several probably continued dividing, with progressive dilution of the label. Others, however, apparently escaped the proliferative compartment, as they retained a high grain count up to three weeks after the thymidine was given. There is also a theoretical possibility that some were lost either by migration from the pericryptal sheath to the lamina propria, or by sloughing off into the intestinal lumen (Marsh and Trier 1974); however, no histological evidence was found in this or previous studies to support such a possibility.

What is the turnover rate of the pericryptal fibroblast population? Although the length of the cell cycle time (Tc) and its phases as well as the proportion of fibroblasts involved in the proliferative compartment (GF) cannot be computed from the above data, the turnover of the population as a whole can be approximated using the quotient of the labelling index (LI) by the DNA synthesis time
(Ts). Indeed, the turnover rate is given by $\frac{\mathrm{GF}}{\mathrm{Tc}}$ which itself is equal to $\frac{\mathrm{LI} \text {. As }}{\mathrm{Ts}}$ Ts varies little in mammalian cells, the present observation of a low labelling index indicates that the pericryptal fibroblasts constitute a slowly renewing population. Considering that Ts is rarely less than six hours or more than 12 hours (Cleaver, 1967), their turnover time ranges between 10 and 20 days, or several times longer than that of epithelial cells. Whether the fibroblasts have a very long cycle time or a small proliferative compartment cannot be determined with the available data.

The present finding of a low labelling index is in good agreement with the previous papers on the subject. In their study of the pericryptal fibroblasts of the jejunum, Marsh and Trier (1974) reported a labelling index of $0.53 \%$ and $3.19 \%$ in mice given six intraperitoneal injections of ${ }^{3} \mathrm{H}-\mathrm{TdR}$ at hourly intervals and killed six and 12 hours respectively after the first injection. Similarly, in the colon of rabbits given one injection of the radionuclide, Pascal et al. (1968) observed no more than seven labelled fibroblasts per 100 scored crypts. This number was increased to 48 per 100 crypts after five sequential injections. In a study on the rabbit jejunum, Parker et al. (1974) observed that, two hours after a multiple dose-pulse of ${ }^{3} \mathrm{H}-\mathrm{TdR}$, nearly 26 times as many epithelial cells as subepithelial fibroblasts were labelled. This ratio increased to as much as 112,48 hours after ${ }^{3} \mathrm{H}-\mathrm{TdR}$, clearly indicating that 'the rate and/or number of divisions of labelled epithelial cells over the first two days after ${ }^{3} \mathrm{H}-\mathrm{TdR}$ injection apparently exceeds that of the labelled fibroblasts'.

In the present work, the distribution of proliferating fibroblasts was found to be slightly predominant along the lower two-thirds of the crypts. This phenomenon was more marked in the rabbit colon (Pascal et al., 1968). In the mouse and rabbit jejunum, practically all proliferating fibroblasts were found along the crypts only (Marsh and Trier, 1974; Parker et al., 1974). Interestingly, thus, the location of the proliferative cells from both the epithelium and the pericryptal sheath can be similar. On the other hand, when the location of labelled fibroblasts is followed several days after the injection of ${ }^{3} \mathrm{H}-\mathrm{TdR}$, their proportion becomes progressively equal in all segments of the crypts in the colon, as well as along the villi in the small bowel. This indicates that daughter cells produced lower in the mucosa are progressively redistributed among the entire population. This observation, however, led Pascal et al. (1968), followed by Marsh and Trier (1974) and Parker et al. (1974), to conclude that fibroblasts and 
epithelial cells migrate in synchrony from the base of the crypts to the intestinal lumen. Their conclusion is hard to follow in the light of their own observations. Indeed, a migration process that would occur in synchrony with the epithelial cells and terminate by either some 'sloughing off into the intestinal lumen' or an eventual migration to the deeper layers of the lamina propria, would imply a constant renewal of those fibroblasts with a turnover time similar to that of epithelial cells. This is a possibility we cannot retain, on the basis of the low labelling index of the fibroblasts. There are only two theoretical possibilities to link a slow population turnover with a rapid migration. One is to admit that only a small subpopulation of fibroblasts rapidly proliferate and migrate, among, however, a large non-proliferating, stable population. This possibility is unlikely and in no way compatible with the hypothesis of an orderly migration of the whole subepithelial fibroblast population in synchrony with the epithelial cells. The other theoretical possibility is to admit that, after migrating in synchrony with the epithelial cells from regenerative zone to the exfoliative zone, the fibroblasts migrate to the lamina propria and, at later time intervals, return to the pericryptal compartment at the base of crypts ('recycling'). Again, this possibility is unlikely. Such a phenomenon, indeed, has never been observed in other biological systems. In addition, it is not supported by the observations of Kaye and his colleagues (1968) that pericryptal fibroblasts along the lower crypt, which appear to be rather undifferentiated, are histologically different from those along the upper crypt and mucosal surface, which take on the appearance of differentiated fibrocytes. Moreover, no histological evidence has ever been brought forward to show that fibroblasts were sloughed off through the surface basal membrane, or accumulated in the region of the lamina propria.

All the evidence, therefore, indicates that the pericryptal fibroblasts constitute a slowly renewing cell population. Although some migration of the fibroblasts cannot be excluded, we are of the opinion that the concept of a continuous orderly migration in synchrony with the epithelial elements cannot be supported by the present or previously published data.

On the other hand, silver impregnation studies have indicated that the basal lamina, another component of the pericryptal sheath, also has a turnover time far in excess of that of the epithelial cells (Walker, 1972; Rahier et al., unpublished data). The pericryptal sheath is therefore to be viewed as a rather stable structure upon which the epithelial elements migrate while undergoing differentiation.
The authors wish to thank Dr. Eleanor E. Deschner, Professor H. Firket, and Dr. H. Barbason for reviewing the manuscript, Mrs. R. Raux and Mr. H. Withofs for skilful assistance, and Ms. A.Ch. Lemaire for help in the preparation of the manuscript.

\section{References}

Cairnie, A. B., Lamerton, L. F., and Steel, G. G. (1965). Cell proliferation studies in the intestinal epithelium of the rat. 1. Determination of the kinetic parameters. Experimental Cell Research, 39, 528-538.

Chang, W. W. L., and Nadler, N. J. (1975). Renewal of the epithelium in the decsending colon of the mouse. IV. Cell population kinetics of vacuolated-columnar and mucous cells. American Journal of Anatomy, 144, 39-56.

Cleaver, J. E. (1967). Thymidine Metabolism and Cell Kinetics, (Frontiers of Biology, vol. 6, Edited by A. Neuberger and E. L. Tatum). pp. 126-129. North-Holland: Amsterdam. Kaye, G. I., Lane, N., and Pascal, R. R. (1968). Colonic pericryptal fibroblast sheath: replication, migration and cytodifferentiation of a mesenchymal cell system in adult tissue. II. Fine structural aspects of normal rabbit and human colon. Gastroenterology, 54, 852-865.

Lipkin, M., and Quastler, H. (1962). Cell population kinetics in the colon of the mouse. Journal of Clinical Investigation, 41, 141-146.

Marsh, M. N., and Trier, J. S. (1974). Morphology and cell proliferation of subepithelial fibroblasts in adult mouse jejunum. 2. Radio autographic studies. Gastroenterology, 67, 636-645.

Mathan, M., Hermos, J. A., and Trier, J. S. (1972). Structural features of the epithelio-mesenchymal interface of rat duodenal mucosa during developemnt. Journal of Cell Biology, 52, 577-588.

Messier, B. (1960). Renewal of the colonic epithelium of the rat. American Journal of Digestive Diseases, 5, 833-835.

Messier, B., and Leblond, C. P. (1960). Cell proliferation and migration as revealed by autoradiography after injection of thymidine- $\mathrm{H}^{3}$ into male rats and mice. American Journal of Anatomy, 106, 247-262.

Parker, F. G., Barnes, E. N., and Kaye, G. I. (1974). The pericryptal fibroblast sheath. IV. Replication, migration, and differentiation of the subepithelial fibroblasts of the crypt and villus of the rabbit jejunum. Gastroenterology, 67, 607-621.

Pascal, R. R., Kaye, G. I., and Lane, N. (1968). Colonic pericryptal fibroblast sheath: replication, migration and cytodifferentiation of a mesenchymal cell system in adult tissue. I. Autoradiographic studies of normal rabbit colon. Gastroenterology, 54, 835-851.

Quastler, H., and Sherman, F. G. (1959). Cell population kinetics in the intestinal epithelium of the mouse. Experimental Cell Research, 17, 420-438.

Sawicki, W., and Rowinski, J. (1970). Proliferation kinetics in epithelium of guinea-pig colon. I. Variations depending on crypt length and its localization. Cell and Tissue Kinetics, 3, 375-383.

Sawicki, W., Rowinski, J., Maciejewski, W., and Kwarecki, K. (1968). Kinetics of proliferation and migration of epithelial cells in the Guinea pig colon. Experimental Cell Research, 50, 93-103.

Walker, F. (1972). Basement-membrane turnover in the rat. Journal of Pathology, 107, 119-121. 